\title{
EU E A SENHORA SABEMOS O QUE É VIVER NA ROÇA, NÉ, VIADO? FOGÃO A LENHA, MACH(AD)OS E CRIANÇAS
}

\section{YOU AND ME BOTH KNOW WHAT IT IS TO LIVE IN THE COUNTRY, DON'T WE, BITCH? WOOD STOVE, AXES AND CHILDREN}

\begin{abstract}
Alexsandro Rodrigues ${ }^{1}$
Steferson Zanoni Roseiro ${ }^{2}$

RESUMO

Este ensaio fabula narrativas e experimentações de subjetividades e crianças no território rural, problematizando as histórias contadas à beira de fogões a lenha. As crianças dessa escrita desconfiam das boas intenções dos dessas histórias, pressentem ameaças percorrerem a pele. Elas sabem que, na repetição das narrativas, há uma fábrica de herdeiros mach(ad)os. Essas histórias não as atraem. Ainda que portem marcas da força do machado, quebram o cabo do machado e, com os restos, viram e fazem outras coisas. É na fenda, no corte como acontecimento que sacis, lobisomens, iaras e curupiras lhe fazem companhias aventureiras. As explorações nos espaços de sociabilidade no interior permitem as crianças da roça borrar os limites do corpo-gênero-sexo e a força do dispositivo machado. $\mathrm{E}$ as crianças o fazem pelo simples fato de que, ali, fazendo caminho por entre matas e à beira do riacho, elas encontram mais possibilidades de liberdade para ocupar e experimentar.
\end{abstract}

Palavras-chaves: Roça. Fogão a lenha. Crianças. Machado.

\section{ABSTRACT}

This essay fables narratives and experimentations of subjects and children in the rural territory, problematizing stories told by wood stove. The children of this writing mistrust the good intentions of these stories, they sense threats wandering their skin. They know that, in the playlist of the narratives, there is an axe heir factory. To these children, those stories have no appeal. Yet they have marks of the axe's strength, they break the axe handle and, with the leftovers, they become and do something else. It is in the crack, in the cut as a happening that Sacis, Werefolves, Iaras and Curupiras come along with them in adventures. The explorations in socializing space of the rural territory allow the children in the country to smudge the limits of the body-gender-sex and the strength of the axe advice. And the children do that by simple fact that, there, wandering into the woods and by the stream, they find more possibilities of freedom to occupy and experiment.

Keywords: Farm. Wood stove. Children. Axe.

\footnotetext{
${ }^{1}$ Atualmente é Professor do Centro de Educação e do Programa de Pós-Graduação em Psicologia Institucional da Universidade Federal do Espírito Santo. Doutor em Educação pela Universidade Federal do Espírito Santos. e-mail: xela_alex@bol.com.br

${ }^{2}$ Doutorando em Educação pela Universidade Federal do Espírito Santo e Professor da Rede Municipal de Cariacica/ES. e-mail: dinno sauro@hotmail.com
} 


\title{
novistet \\ 政
}

\section{INTRODUÇÃO}

\begin{abstract}
As narrativas são cortadas pelas linhas de poder, mas elas não existem num campo tranquilo de imposição. Ao contar histórias contaminadas pelos significados dominantes, elas tentam estabelecer e fixar identidades hegemônicas. Entretanto, as identidades e subjetividades sociais existem num terreno de indeterminação, num terreno de significados flutuantes. Os significados produzidos e transportados pelas narrativas não são nunca fixos, decididos de uma vez por todas. $\mathrm{O}$ terreno do significado é um terreno de luta e contestação. Há, assim, uma luta pelo significado e pela narrativa. Através das narrativas, identidades hegemônicas são fixadas, formadas e moldadas, mas também contestadas, questionadas e disputadas (SILVA, 1996, p.176).
\end{abstract}

Histórias macabras - ricas em detalhes de noites de lua cheia e lobs-omem ${ }^{3}$, de animais-homens, sempre a meio-caminho de quem deveríamos nos desviar e cheias de pitadas de monstruosidades - colocam-nos a tremer de medo na mesma intensidade em que nos fascinavam a querer saber mais do mesmo e ouvir de novo.

Algumas crianças, por amar o desconhecido e as monstruosidades atrativas, com essas histórias são impulsionadas a continuar na aventura de querer/produzir outros possíveis e estabelecer encontros afetivos com lobs-omem!

Com requinte de crueldade, violência e morte, histórias de matanças de crianças, de crianças abandonas em estradas e florestas à sua sorte, em condição de trabalho escravo, exploradas e maltratadas nos foram contadas à beira do fogão a lenha no interior deste país.

A beira dos conhecidos fogões a lenha, à luz de lamparinas e velas, lá estávamos nós, crianças da roça, abraçados, aquecidos e alimentados por quitutes e histórias de lobs-omem. Entre lenhas, fogões, fogueiras, fogo, caldeirões, macha(dos), espingardas, sapos, cobras, gatos pretos e lobs-omem, lá estávamos nós ouvindo histórias. Ouvindo histórias, aprendíamos coisas sobre corpo, identidade e... lobs-omem. Aprendíamos com essas histórias sangrentas principalmente sobre o que não deveríamos ser e desejar. Abrindo cortes no tempo e no corpo, essas histórias, que fabricam corpos-crianças, reiteravam identidades

\footnotetext{
${ }^{3}$ Tentativa de produção de outros sentidos para a palavra lobisomem.
} 


\section{Revista \\ Debates Insubmissos}

hegemônicas, muitas vezes genocidas, colonizadoras, fundamentalistas, sexistas e racistas. Mas deixavam à deriva os tais lobs-omens...

Histórias nos eram contadas com o sangue de pessoas que sobram, com o sangue de pessoas que, no fim, não fariam falta. Histórias que afiavam lâminas e línguas de mach(ad)os; histórias que, no calor do aconchego, contavam, vitoriosas, sobre as vidas e crianças infames apedrejadas pelas mãos que empunham os mach(ad)os e outras bravatas. Nas casas da roça, o mach(ad)o atrás da porta, ou bem ao lado do fogão a lenha, não nos deixavam esquecer da força de suas lâminas/línguas e de quem podia manipulá-lo. As histórias sequer esperam seus efeitos - apenas cortam. Cortam! Cortam a carne, cortam a pele, os cabelos, as posturas, as línguas.

\section{O sangue escorre.}

Para algumas crianças, esse é o fim. A lâmina do mach(ad)o lhes talha com tal precisão que, depois de tolhida, há apenas os mach(ad)os e suas brutalidades.

Outras de nós, crianças que nascem em noites de lua cheia e que entende as línguas estrangeiras dos lobs-omem, brincamos com as palavras. Aproveitamos a proximidade com os fogões a lenha e fazemos um caldo com as palavras e histórias que nos jogam. Pedimos os mach(ad)os e alegamos que vamos cortar a lenha. Talvez até cortemos! Muito se pode fazer com uma tora de lenha em mãos na calada da noite ou nas estradas que nos levam ao riacho. Se nos cobram o mach(ad)o, quebramos, com nossos corpos, o cabo/pau do mach(ad)o e, com a lâmina solta, brincamos de fazer entalhes sobre a pele para anormalizar a figura das narrativas. Do corte da lâmina, nascem os sacis, os lobs-omens, as iaras, os curupiras...

Algumas de nós, seguindo à deixa do rock bicha de Secos e Molhados, fazemos as superstições e mach(ad)adas virarem.

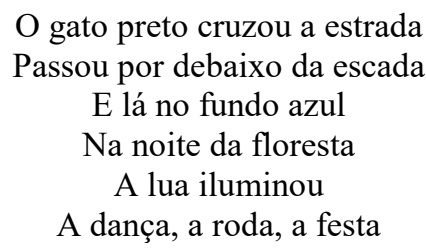




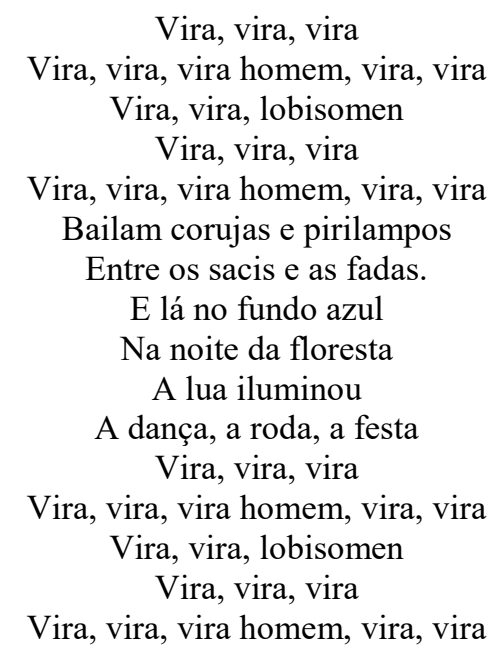

Somos crianças das encruzilhadas, crianças do vira-vira. Todo tipo de história das mach(ad)ezas já foi contada a nós e sempre afirmaram haver nelas o aconchego do fogão a lenha. E delas fizemos piadas, interlúdios, inventamos outras lendas. Uivamos à luz do luar e encontramos, nas moitas, os lobs-omens. Sentadas à beira do fogão a lenha, hoje contamos histórias de crianças que nascem do flerte com o folclore, que nascem das escapadas atrás das moitas. Sentadas à beira do fogão a lenha, cantamos na língua que faz estripulias.

Ora pois, assim brincamos nesse ensaio! Cantos e histórias nessa língua de estripulias não nos faltam. Interessam-nos justamente contas as gafes do mach(ad)o, os vira das criançasfolclóricas, das crianças de roça que fumaceiam pelos ares. Sentávamos, enquanto crianças, à beira dos fogões a lenha e ouvíamos as paixões das línguas e lâminas dos mach(ad)os. Até que não mais; até que, num rompante, somos nós ali, à beira do calor da lenha, ajeitamos a madeira para trazer ao ambiente um pouco de fumaça.

Parcialmente ocultas pela fumaça, perdemos as estribeiras e contamos a todos o ruir das lâminas dos mach(ad)os. Aconcheguem-se!

\section{O MULA-SEM-CABEÇA OU DOS CORPOS PRODUZIDOS NO DISPOSITIVO DO MACH(AD)O}




\section{Revista
Debates Insubmissos}

As crianças que crescem à beira do fogão a lenha sempre têm história para contar. A vida do interior é cheia de dedos, histórias, fuxicos e sussurros. À beira do fogão, algumas figuras colocam a panela para fazer a polenta e o verdadeiro frango da roça, fritam o bolinho de aipim em gordura de verdade e no lugar do tão conhecido chocolate quente urbano, as crianças esquentam as mãos e a garganta com uma caneca que parece um mingau doce de canjica.

Algumas crianças aguardam ansiosas a história do avô, do pai, do tio ou do irmão aquelas histórias cafonas, cheias de punho, sangue e mach(ad)os. Outras, porém, preferem olhar para o fogão e sonham com a fumaça.

Sim, há todo um elemento da fumaça que essas crianças evocam para produzir a penumbra em que as coisas se borram, em que as histórias dos mach(ad)os gaguejam e cortam às cegas o que veem pela frente.

Para essas crianças, a fumaça é sinal de uma festa a começar. Por isso, dançam, rodam, fartam-se em risos. Feito fumaça, elas mesmas escapam pelas frestas da prisão familiar. Obviamente, não gostam das chaminés, do caminho regrado. Entendem que sua arquitetura as levam a lugares já conhecidos! Pela chaminé, lobs-omem vira-sopa, vira-homem e sonham com mach(ad)os!

Elas, no lugar, preferem a penúria, os olhos cerrados e a dubiedade.

É que elas, na verdade, veem nas histórias de mach(ad)adas todo um aparato do dispositivo do sistema sexo-gênero e seus privilégios (PRECIADO, 2014). Ainda que nada entendam disso, sabem, desde pequenas, que são os mach(ad)os que lhes cortam os cabelos, que lhes exige a bruteza e a secura do existir. Fomos essas crianças! Foram incontáveis as vezes que ouvimos um mach(ad)o nos dizer, entre os dentes, para manter o pulso mais firme, para nos preocuparmos menos com a panela no fogo, para não falarmos o desnecessário. "Desse jeito, não vai segurar o mach(ad)o nunca" era sempre a sentença final.

Assim reafirmavam o dispositivo sexo-gênero a cada reunião familiar. E, conforme lembra Foucault (2006, p. 244), o dispositivo é um conjunto heterogêneo que engloba 


\section{Revista \\ Debates Insubmissos}

[...] discursos, instituições, organizações arquitetônicas, decisões regulamentares, leis, medidas administrativas, enunciados científicos, proposições filosóficas, morais, filantrópicas. Em suma, o dito e o não dito são elementos do dispositivo. O dispositivo é a rede que se pode estabelecer entre estes elementos.

Sem nenhuma cerimônia, o gume do mach(ad)o dita as linhas, as expressões, os cortes e os silêncios disponíveis quando os corpos das roças se encontram. Pode até ser que, conforme sugeria Foucault, as histórias contadas à beira dos fogões sejam narrativas sem proprietários, que talvez se façam um dispositivo sem sujeito (FOUCAULT, 2014), todavia, os privilégios dos mach(ad)os não tardam em aparecer.

A bem da verdade, eles esbanjam seus privilégios debochando de todas as crianças que se apaixonam pela fumaça, pelas panelas ou pelas histórias não contadas sobre os mach(ad)os.

Contra essas crianças, amolam-se o gume dos mach(ad)os como, nas cidades, amolamse as facas (BAPTISTA, 1996) no ódio dosado contra tantas formas de vida.

A diferença é que, na roça, os cortes são dados com violência explícita - não disfarçam em discursos, em arguições, em histórias para criança dormir. Ali, quando o dispositivo do mach(ad)o não cumpre sua função, apelam logo para o seus cabos de pau para açoitar corpos e as lâminas para cortar e fazer sagrar. No tempo de duração dos mach(ad)os, criam paisagens políticas pensadas para a infância e um certo corpo-criança que, a fim e a cabo, dará conta de empunhar sua mach(ad)eza para si mesmo tanto quanto para seus colegas. Os corpos produzidos nesse dispositivo não são corpos afoitos à beleza da fumaça inebriante; antes, são corpos que expressam em seus corpos nada mais que a bruteza.

Todos conhecemos essas crianças! Mesmo nas roças, sabemos como localizá-los. São os meninos que rolam no chão trocando socos pelos motivos mais estúpidos - "Eu que vou cuspir nela!" -; os que veem nas outras crianças o próximo alvo de chacotas; os que estufam o peito para contar seus ganhos e conquistas.

No dispositivo dos mach(ad)os, assim deveria ser toda criança: possessiva, pronta para a briga e enxergando nos outros apenas fraquezas.

Para nosso infortúnio, muitas das crianças com quem crescemos, restou apenas a dureza dos mach(ad)os que se espalhavam por sobre os fogões a lenha. Mesmo dentro das 


\section{Revista (O) \\ Debates Insubmissos}

panelas, parecia haver apenas ingredientes cortados a lances de machadadas. E, uma vez cortados pelos mach(ad)os, tolhe tudo o mais que não for digno de bruteza. Assim, alquimicamente, misturam-se nessas panelas os ingredientes de uma sexualidade digna dos mach(ad)os, produzem corpos e subjetividades esculpidos para uma configuração familiar hegemônica. Homens e mulheres talhados com os nacos dos mach(ad)os foram, um dia, essas crianças que acreditavam no conforto dessas panelas e de suas comidas quentes.

Ou os corpos se esquentam com essa comida das mach(ad)adas que almeja a bruteza como produto final, ou se aquece com a língua e a lâmina do mach(ad)o. Não ao acaso, a comida, decididamente, parece demasiado apetitosa nessa situação.

Assim se multiplicam as crianças herdeiras dos dispositivos de mach(ad)os nos interiores de nosso país. Crianças que, iniciadas na regra do mach(ad)o, não poupam esforços em alimentar a lâmina de corte do dispositivo. Se se requer desse dispositivo que nem o bigode de um camarão ameace a mach(ad)eza dessas crianças (SÁEZ; CARRASCOSA, 2016), os bons herdeiros da lâmina do mach(ad)o multiplicarão - em seus arredores - as lâminas cegas e as facas de dois gumes. Enxergarão, para todos os lados, as crianças que brincam com fumaça e fazem comida e contarão, aos sete ventos, sobre elas em tons maliciosos.

Não sem antes torturá-las e praticar nelas a própria bruteza do mach(ad)o.

E as histórias das crianças que sofrem nas línguas e lâminas dos mach(ad)os não nos faltam. É o Joacir que todo dia corria para assoprar um dente-de-leão e, alvo das criançasmach(ad)os, acaba sendo torturada por folhas de pinhão. É o Aristóbalo que, numa tarde qualquer, resolve nadar e brincar de Iara com as meninas no rio e, por um acidente do destino, descobre depois que todas as suas roupas sumiram e que precisa voltar para casa pelado. É o Teobaldo que finalmente é convidado para brincar com os herdeiros-mach(ad)os de escondeesconde e, horas depois, descobre que todos os outros meninos há muito abandonaram a brincadeira e deixaram ele sozinho escondido em algum lugar.

Evidentemente, essas histórias são contadas junto a amigos, familiares, conhecidos. Multiplicam-nas com o riso da lâmina rota de um mach(ad)o bem afiado. 


\section{Revista \\ Debates Insubmissos}

Pelas redes de poder, as histórias selecionadas vazam intenções e frustrações. Pouco importa se ninguém a seleciona com a vil intenção de poder - infelizmente, para muitas dessas crianças, é assim que elas funcionam, como acordos dispersos que enaltecem os privilégios das mach(ad)ezas! Contamos histórias e com elas somos tramados. Nada existe de inocente nas escolhas que fazemos, nas contações que ouvimos e multiplicamos! Somos constituídos por histórias. De nossos repertórios, de nossos baús da memória, selecionamos o que nos marca e nos corta.

As histórias das mach(ad)adas evocam justamente o controle sobre o fluxo das possibilidades do corpo. Usadas ao sabor de seus contadores, elas marcam e barganham, em operações de poder, as subjetividades das crianças! Contando histórias, os mach(ad)os reiteram marcas de gênero, de sexualidade, de raça, de classe, de território e nação. Com Tomaz Tadeu da Silva (1996, p. 176),

Podemos entender o conceito de narrativas para muito além daqueles gêneros formalmente conhecidos como tais: o romance, o conto, o filme, o drama. Existem muitas práticas discursivas não reconhecidas formalmente como narrativas, mas que trazem implícita uma história, encadeiam eventos no tempo, descrevem e posicionam personagens e atores, estabelecem um cenário, organizam os fatos num enredo ou trama. Par todos os efeitos, funcionam como narrativas.

A casa, a cozinha, os quartos, o quintal, a família e suas histórias - tudo funciona como um convite às crianças para talharem em si mesmas as marcas das mach(ad)ezas tão típicas da vida do interior. E alguns corpos, tão familiarizados com essas marcas, pedem cotidianamente por mais, clamando o famoso "Conta de novo!" toda vez que acaba uma história em que, mais uma vez, é o corpo apaixonado pela fumaça e pelo misticismo que sofre. Nas cozinhas do interior, no cair da noite, no estalo das brasas ardentes, com as sombras que se formam nas paredes esfumaçadas pelos usos, intensificamos, com quem nos abraça, os sentidos necrófilos que podem vir a ter o outro, os que valem menos, os monstros, as bruxas, as assombrações, o folclore e que se desviam dos dispositivos dos mach(ad)os.

A cada história acrescida ao caldeirão das mach(ad)ezas, outros temperos da vida são retirados. Adicionam-se os temperos rudimentares; tiram-se as especiarias, os temperos apimentados, os agridoces, os exóticos. Nessas terras, semeiam-se plantas para serem colhidas a machadadas. 


\section{Revista \\ Debates Insubmissos}

Nada melhor que o bom e velho plantio da batata doce, do aipim, do inhame.

Selecionar é uma operação das tramas do poder.

Para as crianças da roça, os mach(ad)os funcionam com atrativo e repulsa -brilham em suas histórias de corte e sangue e são apresentados aos vizinhos e familiares com muito orgulho. E todas as vezes que a ordem é ameaçada, ouve-se de um guardião da verdadeira mach(ad)eza: "Este mach(ad)o, que em breve será de Jatobias, pertenceu a meu pai, que recebeu de meu avô, que pertenceu a seu avô antes de seu tempo... seu corte nunca falha. Corte sem dó".

Escondem-se, deveras, as crianças temerosas das histórias de mach(ad)os.

Quando lhes resta alguma parca alternativa, viram as famosas mulas-sem-cabeça. Os famosos corpos sem rostos que, na calada da noite, adentram as moitas populares para lhe massagearem o ego, para ejacular o anseio da mach(ad)eza. Quando a lenha do fogão já está fria e a lâmina do mach(ad)o já não mais esquenta, alguns corpos saem à louca a procurar alguns Sacis, Curupiras e Iaras para lhes assegurar um gozo difícil. Seja no meio do escondeesconde, atormentando o Muriel ou em uma típica brincadeira de mach(ad)os, algumas crianças tornam-se mulas-sem-cabeça por alguns minutos - apenas o tempo precoce do prazer por um corpo não tão regrado pelo mach(ad)o.

"Vamos brincar de tomar banho no rio de novo amanhã?", pergunta uma criança-Iara nessas raras ocasiões em que uma criança-mach(ad)o se permite ser outra coisa. A resposta é um corte afiado. “Quer apanhar, viadinho?”. A criança-mula-sem-cabeça já voltou à dureza do mach(ad)o - quão logo chegam ao ápice que seu medo lhes permite, voltam a ser bravos guardiões do maldito dispositivo. E somem para o aconchego das brasas frias de suas casas.

Uma vez escondidos em sua conformidade de mach(ad)eza, sentem que podem, finalmente, relaxarem. Pensam, iludidos, que o dispositivo de mach(ad)os não os conhece, não lhes enraba também nessas fugas. Doce ilusão. $\mathrm{O}$ dispositivo dos mach(ad)os sabe - e muito bem! - dos corpos que viram mulas-sem-cabeça, das crianças-mach(ad)o que, em um momento ou outro, valem-se das outras crianças para sorver da vida um novo gozo. Inclusive, 
os mach(ad)os estimulam tais escapadas. Servem, antes de mais nada, para afiar a língua e o gume do mach(ad)o.

A cada vez que uma criança-mula-sem-cabeça volta para casa, ela conta uma história de corte novo que aprendeu com sua mach(ad)eza. A cada nova história, mais uma criança treme e esmaece vendo seu próprio sangue escorrer.

\section{IARAS, SACIS E CURUPIRAS OU DAS CRIANÇAS QUE NÃO TÊM MEDO DA CUCA}

Ora, pois! Mas nem tudo são mulas ou mach(ad)adas!

No interior desse país, em terras mineiras e capixabas, as cozinhas abertas acabam por ser convite para um bom dedo de prosa para todos os corpos. Um gole de café e um prato de comida, com saberes e sabores, a ninguém se nega! Do lado de fora de casa, de vez enquanto um grito "Tô chegando!" se faz ouvir e, mais do que de pressa, a comida - sempre pronta! - se

multiplica. "Bota água no feijão que Jeremias está chegando!". De algum modo, o grito "Tô chegando!" é sempre familiar. Exige, de quem naquela casa habita, um modo de se abrir às histórias de quem vem chegando. No momento em que os habitantes daquela casa dão as boasvindas ao estranho-familiar que ali perambula, elas se abrem, também, de ouvidos. Ainda que o mach(ad)o seja uma ameaça constante, quando se senta para comer com quem vem de fora, ele fica atrás da porta. À mesa, senta-se de corpo e de ouvidos abertos.

Assim, portanto, invade-se os jogos das mach(ad)adas! Sem aviso prévio e chegando sempre de supetão. Afinal, no interior, é sempre assim que se chega a uma casa: sem cerimônias, sem enrolações. Chega-se chegando, com muito tempo para a prosa, os casos, as fofocas e os para o que os afetos permitirem.

Nas cidades pequenas, por dentro da vida da roça, somos instados a sonhar o casório precoce e com as plantações de todos os tipos. Os sonhos urbanos de príncipes encantado e princesas cedem lugar da boa moça e do rapaz de mão calejadas. Ensinam-nos bem pouco ou 


\section{Revista
Debates Insubmissos}

quase nada a sonhar e, nas parcas vezes que sonhamos, sonhamos com prédios altos, com a vida nas cidades.

As crianças desobedientes, por sua vez, sonham com outras possibilidades.

Alguma coisa acontece no entre das narrativas das mach(ad)adas e nos faz afirmar, conforme sugere Tomaz Tadeu da Silva (1996), que os significados e os usos dessas narrativas são fumacentos e esvoaçantes.

Nas roças em que crescemos, vez ou outra escapava uma história que o mach(ad)o não dava conta de cortar. Nunca fomos muito dados a príncipes e princesas, mas aprendemos a sonhar com as peraltices do Saci, com os encantos do Boto e as melodias da Iara. Vez ou outra, uma criança se pergunta, enquanto ouve mais e mais daquelas histórias enfadonhas de vexame e massacre do dispositivo do mach(ad)o, se é possível sonhar com o Curupira, o Boitatá ou o Lobisomem.

Ainda que os corpos em comum acordo com o dispositivo do mach(ad)o lhe ameacem com a Cuca - "Se você acreditar nessas histórias, a Cuca vai te pegar!" -, essas crianças, porque sonhadoras, aprendem a delirar com o rapto da Cuca e brincam, desavergonhadamente, com as figuras folclóricas que povoam suas cucas recheadas de esperança.

As famílias, treinadas pela lâmina-língua do mach(ad)o, adoram jogar com a Cuca e em suas variações. Quando percebem que o corte e o talhar do mach(ad)o não funciona como deveria sobre algumas crianças - essas nascidas à meia-noite -, tentam entrar no próprio jogo das crianças e colocam o sequestro como um risco que beira à vida. Jogam os dados e torcem pelo pior.

Ora, o que não entendem é que o machado já funciona como uma operação de sequestro. Ao talhar sobre suas peles os sulcos e os caminhos que lhes são permitidos, ao lhes garantirem uma seguridade insana e imobilizadora - sempre em prol do que é melhor para elas! -, o machado sequestra já os futuros compossíveis. "Será que eu consigo controlar o vento e rodopiar por aí abaixando as calças de todo mundo que nem o Saci?”, pergunta uma criança. De imediato, a ordem do mach(ad)o é negar-lhe o possível. 


\section{Revista \\ Debates Insubmissos}

Sequestro imediato das possibilidades de existência.

Dizendo sempre para o bem das crianças, o mach(ad)o, a família - mas também algumas escolas, algumas brincadeiras... - e outras tantas ações ou instituições sequestram a vida justamente por impedir que os movimentos das crianças expandam-se em corpos e criações não previstas (SCHÉRER; HOCQUENGHEM, 2016). É preciso sequestrar para manter certa estabilidade, para que os corpos não derivem infinitamente. E, dentro da lógica de um dispositivo de mach(ad)adas que impõe seus cortes e talhos no sistema de gênero-sexo, énos imperativo compreender que os sequestros das infâncias está intimamente relacionado com o sequestro das expansões de gênero-sexualidade.

Todavia, apesar de todo o esforço, algumas das crianças não se assustam com a figura da Cuca. Antes, veem nela o encanto por um caminho desconhecido, por uma possibilidade para além das regras dos mach(ad)os.

Tão logo são ameaçadas com a figura da Cuca, as crianças começam a sonhar com ela. E muito se engana quem pensa estar aí um medo irracional, um pesadelo ou qualquer outra bobeira assim! As crianças que se deparam com a Cuca - ainda que em sonhos! - são já raptadas de suas realidades sequestrantes e começam a delirar com corpos inexistentes. Passam a ver, para todos os lados, vidas estranhas e se indagam pela produção desses outros corpos.

Em suas paixões pelas histórias de outra ordem, as crianças nascidas à meia-noite sopram fumaças que envolvem a bruteza dos mach(ad)os em um intoxicante mundo desconhecido. Entram em polvorosa com as transformações do próprio corpo. Trilham caminhos que as levam a riachos tão bonitos que nenhuma rudeza ali é cabível. Nesses lugares - córregos, beiras de cachoeira, riachos, lagos -, meninos e meninas despem-se de seus cortes e de suas roupas e fazem o vira de seus corpos encontrarem a lenda da Iara. Ali, brincando, não há o temor ou a vergonhice do corpo-genitália-masculina ou corpo-genitália-feminina. Elas pactuam de um acordo mútuo: sabem que as mães deles jamais deixariam se banharem naquelas águas! Então, brincando, tomam todos banhos pelados. Afinal, desse jeito, podem muito bem se secarem depois e chegarem em casa com as roupas secas, como se nada tivesse jamais acontecido. 
Uma vez começadas as fugas do dispositivo das mach(ad)adas e as novas aproximações afetivas entre as crianças, estabelecem-se laços de um material que os mach(ad)os não conseguem compreender e, por isso mesmo, muitas vezes falham em cortar.

Ora, se o dispositivo da mach(ad)ada funciona por cortar as relações, por talhar nos corpos as marcas da bruteza, da secura e do ódio criando em cada um uma marca de gênerosexo demasiado bem definida e completamente apática à vida, basta que alguns afetos emerjam para que o sistema das mach(ad)adas comece a caducar.

Se o mach(ad)o exerce seu controle pelo medo e pelo sequestro de todas as outras possibilidades de vida, os afetos evocam para o plano da existência até mesmo seres que sabemos não serem reais. Basta que o medo ceda lugar ao riso de uma criança para que se forme um pequeno vendaval em algum lugar e uma criança negra encapuzada saia correndo por entre as zonas de corte dos afiados mach(ad)os.

Contra as figuras do controle, emergem crianças folclóricas sempre que um abraço um pouco mais afetuoso é trocado ou que a ameaça da lâmina de mach(ad)o se torne mais engraçada que assustadora. Quando as peraltices de uma criança caducam o corte de um mach(ad)o, os corpos passam a temer bem menos sua língua afiada.

Nesses momentos, as crianças flertam livremente com outras crianças. Viram Iaras em longos mergulhos junto a outras crianças sem se importarem com as genitálias que se escondem entre as pernas - exibem-nas em liberdade. Viram Curupiras enquanto brincam pela mata de esconde-esconde e descobrem-se verdadeiros aventureiros do corpo sem precisarem se esconder em meio às moitas. Viram Sacis que riem debochadamente de tudo o que tenta lhes aprisionar. No limite, deliram com o Boto - o eterno corpo apaixonado - que, um dia, poderia vir a gerar em seus corpos outra vida.

Mal sabem essas crianças que elas já carregam outras vidas em seus corpos.

Em suas brincadeiras, as crianças nascidas à meia-noite vira e volta exploram os limites do corpo. Quando dois desses meninos resolvem fugir para a mata e criar, em meio a folhas secas e arbustos, uma toca, eles sabem que, naquele refúgio, o corpo de um pode ser abraçado, tocado e experimentado sem que, com isso, tenha de ser alvo das mach(ad)adas. Sequer é 
necessário que um jogo sexual esteja envolvido com eles! Muitas vezes, são apenas toques afetivos, carinhosos que, sob o rigor do corte do mach(ad)o, jamais seria visto com bons olhos.

A própria afetividade com os corpos é o que a lâmina do mach(ad)o corta impiedosamente - seja com seu próprio corpo ou com o outro. $\mathrm{O}$ mach(ad)o ensina apenas a cobiçar o corpo, a usar para seu próprio corte e poda. Penetração da carne com derramamento de sangue - eis o longo gozo do dispositivo dos mach(ad)os. Deveras, qualquer uso dos corpos que não derrame sangue é sempre um perigo às mach(ad)adas.

Sabidas de todo esse drama, algumas crianças que escapolem de suas casas na calada da madrugada apenas para ver com o riso - seu e de seus queridos! - os vagalumes que incendeiam o corpo com carinho e esperança.

Nós vivemos essas vidas semeadas pelo flerte entre as infâncias as rupturas com as $\operatorname{mach}(\mathrm{ad})$ adas.

$\mathrm{Na}$ roça, pelas encruzilhadas que caminhamos, provamos e provocamos outras aprendizagens. Desbravamos pontos mais distantes dos riachos e de nossas florestas; como formigas, escavamos pelos subterrâneos de cavernas que inventamos nos milharais. As crianças que nasceram em noites de lua cheia e que aprenderam a decifrar os sinais da fumaça e a língua profanadora das lendas e do folclore brasileiro, logo entram em um eterno vira que hora se apaixona pelos lobs-omem, ora brincam de Iara, de Saci, de Curupira. Se tanto insistem que elas não são seres deste mundo, divertem-se, então, sendo de outro! Elas praticam o território, o corpo, o gênero e a sexualidade dando passos dançados. Elas, ainda que voltando para o familiar, voltam sempre contando histórias que o dispositivo do mach(ad)o não sabe como lidar.

E elas sempre voltam. Aos modos de um Saci que aparece sempre para atazanar qualquer paz, as crianças nascidas à meia-noite retornam as suas casas, botam lenha no fogão, preparam o mingau de fubá e já vão enchendo seus familiares com as histórias que lhes escapam do corpo mais que dos lábios. São os gestos, os trejeitos, os afetos que escapam de sua pele. A família se apavora com aquele estranho que lhes é tão familiar, que os chama de mãe, pai, tio, avó, prima, irmão. 
A criança, num eterno vira, não titubeia. Conta-lhes a paixão pela hora zero, pelos pés virados do Curupira, pelo canto sedutor da Iara, pela peraltice do Saci, pelo fogo da floresta, pelo uivo agudo dos lobs-omens.

\section{LOBS-OMEM, LESB-OMEM, LEBICHOMEM... OU DE COMO MANTER NA LÍNGUA UM UIVO AGUDO}

Ser uma criança da roça implica, sempre, estar em exploração com o próprio corpo. É na roça que as crianças veem e ouvem os corpos serem explorados dos modos mais inusitados. Quem, vivendo na roça, nunca ouviu falar das escapadas atrás das bananeiras, das competições de mijo à sombra do jambeiro ou dos risos dos fofoqueiros que observam toda a movimentação dos corpos escondidos no alto das árvores?

No limite, não é sequer raro conhecer uma história ou outra de um menino que teve sua primeira experimentação sexual com uma vaca, uma cabra ou outro animal qualquer.

Talvez, esses sejam futuras mulas-sem-cabeça. Talvez não. Quem sabe?

As sexualidades de interior, a bem da verdade, borram já e sempre os limites do corpogênero-sexo tão familiar ao dispositivo do mach(ad)o pelo simples fato de que, ali, o corpo encontra mais espaços para ocupar, espaços que, muitas vezes, a cidade barra com maior rigidez.

Os mach(ad)os sabem disso e, por isso mesmo, são manejados com tão mais afinco.

Mas quem consegue vigiar uma criança em meio à verdidão a todo o momento? Quem consegue evitar que, quando os pais, os avós e os primos mais velhos vão para as lavouras, a criança não encontre em seu próprio corpo as zonas de experimentação mais indesejosas? Quem consegue evitar que uma criança não se torne outra com um galho que lhe apetece a pele e a faz delirar? Quem consegue evitar que crianças se encontrem e criem brincadeiras - entre elas - que jamais serão contadas a seus familiares, mas que apenas se tornarão risos e memórias? 


\section{Revista \\ Debates Insubmissos}

Os mach(ad)os cortam em suas histórias, em sua braveza - algumas crianças, contudo, simplesmente fazem proliferar as histórias rasteiras, as histórias criadas em tocas, no topo das árvores e em mergulhos nos riachos.

Contam-nos a velha e sempre baboseira do mach(ad)o e o bom casório, do mach(ad)o e do sangue derramado. As nossas histórias, entretanto, são ricas em reviravoltas, em detalhes inusitados, em picâncias e urtigas. No limiar de uma narrativa nova que se erige em nossos corpos, rimos, até, das perseguições que passamos nas mãos de tantos mach(ad)os.

A ameaça que nos assombra não é mais forte que o uivo agudo dos lobs-omens que nos arrancam a pele com as garras. Apaixonamo-nos por quem nos despe por inteiro, por quem nutre nos olhos a fome e o desejo. Não há absolutamente nenhum controle nessa paixão com os lobs-omens. Na verdade, quando nos envolvemos com eles, damo-lhes outros tantos nomes: lesb-omens, lebichomens...

Apaixonamo-nos, perdidamente, pelos corpos que uivam para o luar.

Sabemos que, na verdade, eles uivam é para toda o mistério envolvido com a lua e os nascidos sob sua luz. E nós, crianças nascidas à meia-noite, flertamos com todos os corpos que nutrem afetos apaixonantes por nós.

Jogamo-nos, por inteiro, em todas as aventuras do corpo.

Basta que a vida aconteça, basta que os corpos encontrem vida uns nos outros, para que, logo, esses encontros se tornem histórias que logo serão contadas à beira do fogão a lenha em cada uma das casas. O tom da história pode até ser jocoso em muitas das vezes, mas basta que nossas histórias sejam contadas para que a vida não se perca.

E elas, decididamente, serão sussurradas.

Afinal, eu e a senhora sabemos o que é viver na roça, né, viado?

\section{REFERÊNCIAS}

FOUCAULT, Michel. Ditos e escritos XI: genealogia da ética, subjetividades e sexualidade. Trad. Abner Chiquieri. Rio de Janeiro: Forense Universitária, 2014. 
FOUCAULT, Michel. Microfísica do poder. Trad. Roberto Machado e Angela Loureiro de Souza. 22. ed. Rio de Janeiro: Graal. 2006.

PRECIADO, Beatriz. Manifesto contrassexual. Trad. Maria Paula Gurgel Ribeiro. São Paulo: n-1 edições, 2014.

SÁEZ, Javier; CARRASCOSA, Sejo. Pelo cu: políticas anais. Trad. Rafael Leopoldo. Belo Horizonte: Letramento, 2016.

SCHÉRER, René; HOCQUENGHEM, Guy. Coir: álbum sistemático da infância. Trad. Eder Amaral. Rio de Janeiro: UERJ, 2016.

SILVA, Tomaz Tadeu. Identidades terminais: as transformações na política e na pedagogia. Petrópolis: Vozes, 1996.

Submetido em: 22/06/2020

Aprovado em: 16/07/2020 